\title{
Family ties, incentives and development: a model of coerced altruism
}

\author{
Ingela Alger and Jörgen W. Weibull* \\ Carleton University and Stockholm School of Economics
}

\begin{abstract}
SSE/EFI Working Paper Series in Economics and Finance No 681
OCTOBER 24, 2007
\end{abstract}

\begin{abstract}
We analyze the effects of family ties on the incentives for production of effort, where family ties are defined as a mixture of true and coerced altruism between family members. We model families as pairs of siblings. Each sibling exerts effort in order to obtain output under uncertainty. A social norm dictates that a sibling with a high output must share a specified amount of this output with his sibling, if the latter's output is low. Siblings may be truly altruistic towards each other, but not to a larger degree than dictated by the social norm. We compare such informal family insurance with actuarially fair formal insurance.

We show that coerced family altruism reduces individual efforts in equilibrium. However, individuals always benefit ex ante from living in families with coerced altruism, as compared with living in autarky. We show that a certain degree of coerced family altruism is robust as a social norm in a society of selfish individuals. Finally, we show that if family members are sufficiently altruistic to each other, then informal family insurance by way of coerced altruism may outperform actuarially fair insurance programs.

Keywords: altruism, coerced altruism, family ties, insurance, moral hazard.

JEL codes: D02, D13

*We are grateful to Daron Acemoglu, Philippe Aghion, Don Cox, Karen Norberg, Marcus Salomonsson, and Yannick Viossat for helpful comments and discussions. We also thank audiences at Boston College, Boston University, Carleton University, HEC Montréal, SUNY Binghamton, Université de Cergy-Pontoise, Université Laval, the CEA, the EEA, and the Midwest Economic Theory meetings for feedback. The usual disclaimer applies. Jörgen W. Weibull thanks the Knut and Alice Wallenberg Research Foundation for financial support.
\end{abstract}




\section{Introduction}

The strength of family ties appear to vary across countries and over time. In a recent paper, Alesina and Giuliano (2007) find that the strength of family ties has significant effects on various economic outcomes, such as labor market participation, the extent of home production and geographic mobility. Furthermore, it has been argued that individualism was an important force behind the industrial revolution in England. Thus, Max Weber (1951) thought that "the great achievement of [...] the ethical and ascetic sects of Protestantism was to shatter the fetters of the sib [the extended family]. These religions established [...] a common ethical way of life in opposition to the community of blood, even to a large extent in opposition to the family. (p.237)" In his view, a strong sense of solidarity among members of the extended family, coupled with a hostile attitude towards strangers, promotes a culture where nepotism may thrive and counter the efficient development of markets. Likewise, Banfield (1958) thought that the "amoral familism" that he observed in certain parts of Italy was an impediment to economic development.

Motivated by the evidence that family ties vary in strength across cultures, we here pursue the line of thought suggested by Weber, by way of theoretically analyzing the effects of family ties on risk-sharing and incentives. We all face risk in the form of unknown realizations of future states of the world. Risk may in turn lead individuals to seek to pool resources and thereby mitigate severe adverse income shocks on the individual level. However, insurance markets are not well-developed everywhere, and where markets are poorly developed the extended family tends to be an important source of insurance. ${ }^{1}$ This observation leads to the following questions that we seek to answer here. First, how does the insurance provided within the family affect work incentives for its members? Second, does such informal insurance represent an improvement compared to autarky, that is, a situation in which each individual lives by him- or herself and has no access to insurance whatsoever? Third, can informal family insurance be sustained as a robust social norm in a society exposed to norm perturbations and migration opportunities? Fourth, can actuarially fair formal insurance, either by way of a compulsory and efficient social security system or by way of a perfectly competitive insurance market, outperform informal family insurance?

\footnotetext{
${ }^{1}$ In 2003 the total value of insurance premia (life and non-life) as a percent of GDP was 12.48 in the US, 9.85 in France, 1.42 in Turkey, and 1.74 in Mexico (Insurance Statistics Yearbook: 1994-2003, OECD, 2005). In their survey on private transfers between households, Cox and Jimenez (1990) conclude that in developing countries $20-90 \%$ of households receive (private) transfers, which can represent up to $20 \%$ of the average household income. In the U.S. the corresponding figures are $15 \%$ and $1 \%$, respectively. Since the average income of donor households exceeds that of recipient households (Cox, Galasso and Jimenez, 2006), these transfers appear to provide some insurance. Using data from Thailand Miller and Paulson (1999) show that remittances respond to shocks to regional rainfall.
} 
Since formal insurance pools the resources of a much larger number of individuals than informal family insurance does, it is to be expected that perfectly competitive market insurance would be more efficient than informal family insurance. However, while this certainly is true at a fixed level of individual risk, and with verifiable information about individuals' actions, here work efforts, this reasoning neglects the fact that individuals' incentive to undertake risk-reducing efforts depends on the level of insurance and how the insurance is conditioned on their (verified) actions. Such moral-hazard phenomena are analyzed in Helpman and Laffont (1975), Arnott and Stiglitz (1988, 1990) and, more recently, Bennardo and Chiappori (2003). Since formal insurance under such asymmetric information reduces the incentive for risk-reducing efforts, a competitive insurance market equilibrium can at best sustain partial insurance. While individuals' actions typically are their private information with respect to insurance companies, this is typically not the case, at least not to the same extent, with respect to family members who provide informal insurance to each other. Hence, a priori one cannot rule out the possibility that informal family insurance may outperform formal (market or public) insurance in some cases. One purpose of this essay is to theoretically explore this possibility.

The family, on the other hand, may be particularly vulnerable to the Samaritan's dilemma (Buchanan, 1975), which arises due to an altruist's inability to commit not to help out a person in need. This has been shown to lead to several inefficiencies, including suboptimal savings (Lindbeck and Weibull, 1988) and underinsurance by poor individuals (Coate, 1995). It further seems empirically relevant to study a closely related, but distinct form of family tie, namely, when transfers are given because of others' expectations rather than because of an "inner motive." For a long time, Amartya Sen has urged economists to seek a deeper understanding of the implications of the fact that people make many decisions within the realms of the family, see Sen (1983). As Sen (1987) put it: "The mixture of selfish and selfless behavior is one of the most important characteristics of group loyalty, [a mixture which] can be seen in [...] kinship relations." (p.20) Such a tension between, on the one hand, the individual's selfish desires and, on the other hand, the surrounding society's expectations and social norms, may be an important explanatory factor behind economic growth differentials and the different degrees of development in the world. An individual who lives in a society where he or she is expected to share his or her income with other family members, sometimes even with such relatively distant family members as first or second cousins, ${ }^{2}$ may rationally

\footnotetext{
${ }^{2}$ Dostie and Vencatachellum (2006) find that among 500 domestic workers in Tunisia, $40 \%$ see all their wages transferred directly to their fathers; among those who make voluntary transfers instead, the average amount remitted is $40 \%$ of the wages. According to Etounga-Manguelle (2000), people with a regular income in today's Africa are not only expected to provide help in emergency situations; they are also expected to finance the studies of younger members of the extended family, and to contribute to the many lavish celebrations dictated by social rules; see also Mendelek Theimann (2006).
} 
expect to have to transfer so much of her income - if she is more successful than the others in the family - that the motive for making effort in the first place is diluted. The same phenomenon occurs in partnerships between individuals who share output.

To study these questions we analyze a relatively simple model in which risk-averse individuals choose a costly risk-reducing action, "effort," that determines the probability distribution over output levels. We model the motive for sharing resources within a family as a mixture of voluntary and socially coerced altruism, or as a mixture of sympathy and commitment (Sen, 1983). Voluntary altruism is formalized in the usual way, as a positive weight placed on others' welfare, while coerced altruism is formalized as a culturally or socially imposed norm for intrafamily transfers. We determine the equilibrium behavior of individuals in this model, and use these results to seek to answer the questions we ask. Moreover, we allow for the possibility that the answers to these questions may depend on the underlying riskiness of the environment, which in our model is captured by the ratio of the high to the low output level.

We first study atomistic individuals (with no family ties) living in autarky. The optimal autarky effort does not eliminate the risk of getting the low output. If one could pool the risks of a large number (technically a continuum) of individuals, there would therefore exist a welfare-enhancing budget-balanced insurance policy. Insurance can only be secondbest, however, due to moral hazard (an insurance policy cannot depend on the individual's effort). Since atomistic individuals do not anticipate to be helped out by relatives, they would be willing to buy such an insurance policy: insurance markets are expected to develop in societies where family ties are so weak that no resource sharing occurs within the family, independent of the underlying riskiness.

We then turn to the analysis of insurance provided by the family: formally we analyze this as a strategic interaction between two individuals who care about each others' material welfare, either voluntarily or under the coercion of social norms. An individual's total utility is taken to be a weighted sum of both individuals' material utility, which in turn is determined by each individual's work effort and consumption. The weight put on the other individual's material utility is assumed to be non-negative and not greater than the weight put on one's own material utility. This weight can be interpreted in terms of altruism, or, alternatively, in terms of the esteem derived from others who observes and evaluates one's behavior, such as members of one's extended family, village or society at large. By contrast to Alger and Weibull (2007) where we assume that altruism alone determines transfers within the family, here we consider situations in which an individual's degree of altruism differs from that enforced by society. More precisely, we suppose that the interacting individuals live in a society with a social norm that dictates a larger transfer than the individuals' own altruism 
suggests. If the degree of such coerced altruism is strong, individuals feel forced to help each other out. ${ }^{3}$

The players invest effort in production, and output may be low or high. Once the outputs have been realized, these are observed by both individuals, and transfers occur. We assume that an individual is expected to make a transfer to his or her sibling only if own output is high whereas the sibling's is low. We measure the level of coerced altruism by the share of the high output that a rich individual is expected to give to a poor sibling. Consumption is taken to equal the final output available to the individual. In our model it does not matter whether or not individuals observe each other's efforts; this is because we focus on the case where utility is separable in effort and consumption.

We solve this two-player game focusing on the case of individuals with the same loglinear preferences over own consumption and effort. ${ }^{4}$ Then this game has a unique Nash equilibrium. Its qualitative features are as follows. The anticipation of receiving a transfer when poor has a negative effect on an individual's incentive to exert effort. This free-rider effect is well-known from other analyses of altruism. Hence, the equilibrium effort decreases as the degree of coerced altruism increases. By contrast, true altruism has a positive effect on an individual's incentive to exert effort: an altruist may exert more effort in order to have more to give the other individual, an effect we call the "empathy effect" of altruism on effort.

Despite the previous strong emphasis in the literature on the possible moral hazard effect of intrafamily altruism, there seems to be a limited number of empirical studies on this topic. Using data on farmer output in Mali, Azam and Gubert (2005) find that remittances from emigrated relatives have a negative impact on agricultural output. By contrast, Kohler and Hammel (2001) show, using census data for Slavonia from 1698, that the number of different crops grown by a family tended to increase as the nearby extended family increased. The authors were expecting the opposite effect, namely that as a result of insurance a family would invest less in risk-reducing planting strategies. However, our results suggest that there exists an intuitive explanation for this pattern: when a family expects to help another family out, the expected benefit of the risk-reducing planting strategy is increased.

\footnotetext{
${ }^{3}$ Many individuals are willing to pay in order to avoid situations where they feel coerced to behave altruistically, even in the absence of potential social sanctions. For recent laboratory studies showing this, see Dana et al. (2006) and Broberg et al. (2006).

${ }^{4}$ This particular game has not been studied before. Most of the literature on altruism, starting with Becker (1974), assumes one-sided altruism (see also, e.g., Bruce and Waldman, 1990, Chami, 1998, and Lindbeck and Nyberg, 2006). In models with two-sided altruism, typically only one of the players choose an effort (see Laferrère and Wolff, 2006, for a recent survey), or there is no risk (Lindbeck and Weibull, 1988, analyze the effect of two-sided altruism on savings, and Chen and Woolley, 2001, study the intrahousehold allocation of income on private and public goods).
} 
We then find that while coerced altruism induces "involuntary" transfers ex post, such coercion is efficient ex ante in the sense that the equilibrium expected utility is higher than it would be in the absence of coercion - this is true even if individuals are selfish, so that no empathy effect arises. In such situations, it is as if social norms play the role of compulsory but informal insurance.

We use the equilibrium analysis to determine a sufficient condition for coerced altruism to be sustained as a social norm in a society with selfish individuals, where those who deviate from the norm suffer an exogenously given punishment. Numerical simulations suggest that a more severe punishment would be required to sustain a given level of coerced altruism in societies where the underlying riskiness is high. This is quite intuitive, since the benefit from deviating from the norm by not transferring the socially sanctioned share of high output, is higher when the difference between the outputs is large.

Thanks to the mitigating effect of altruism on moral hazard, risk-pooling between individuals (who cannot observe each other's effort) may outperform a competitive insurance market. Compared to formal insurance among a large number of selfish individuals, the benefit of the empathy effect obtained with altruistically motivated transfers between few individuals (say, within a family) may outweigh the limitation inherent in pooling resources of few individuals, as compared with market insurance that pools resources of a large number of individuals. We find that this occurs in environments with low underlying riskiness, since the mitigating effect of altruism on moral hazard is particularly pronounced in these environments. It is important to point out that, when comparing market and nonmarket insurance we use the same measure of performance, i.e., for nonmarket insurance we do not take into account the welfare that the individuals derive simply from being altruistic.

Our base-line model is similar to that in Arnott and Stiglitz (1991): they also allow for an endogenous, risk-reducing effort, and they model family insurance as transfers within pairs of ex ante identical individuals. They address a different question, however: they ask whether, in the presence of insurance markets, supplemental informal insurance provided by the family improves welfare. Moreover, whereas in our model transfers within the family are driven by altruism, in their model family transfers are the outcome of a joint agreement. Thus, in their model, if the family members can observe each other's effort, the joint agreement specifies that total income should always be shared equally, and it specifies the ex ante optimal effort, conditional on equal sharing. Mathematically, this is equivalent to the special case in our model where siblings are fully altruistic towards each other (attach the same utility weight to the other sibling's welfare as to his or her own). Arnott and Stiglitz also study the case where family members cannot observe each other's effort but can enforce transfer agreements: mathematically this is equivalent to the special case in our model where individuals are selfish 
(attach no weight to their sibling's welfare) and make transfers dictated by coerced altruism.

This essay also complements a large literature that seeks to determine the potential of nonmarket insurance in the presence of constraints imposed by limited enforceability. Posner (1980) introduced the idea that nonmarket insurance could be feasible despite limited enforceability, and Kimball (1988) proved this formally. Coate and Ravallion (1993) characterized the best nonmarket insurance arrangement that may be sustained as a non-cooperative equilibrium in a repeated game between with two self-interested individuals. Foster and Rosenzweig (2001) extended this analysis to allow for altruistic individuals, while Genicot and Ray (2003) determined properties of equilibria that deter not only deviations by single players but also by groups of players. Recently, Bramoullé and Kranton (2006) have shown that equilibrium risk-sharing networks where people form pairwise links generally provide partial insurance only. Following the empirical evidence that households are less than perfectly insured in many developing countries (see Townsend, 1994, and the literature that followed his initial contribution), Ligon, Thomas, and Worrall (2002) tested the hypothesis that this is driven by limited enforceability. By contrast to this literature, in our model risk is endogenous through individuals' choice of effort, and we ask whether insurance markets can function if uninsured individuals expect to be helped out by their relatives if in need.

Our model is similar to that in Lindbeck and Nyberg (2006), who analyze altruistic parents' incentive to instill a work norm in their children. The incentive stems from parents' inability to commit not to help their children if in financial need. If the children feel a strong social norm to work (hard), then this reduces the risk that the children will be in need, which is good for the altruistic parents. On the other hand, the parents will suffer with the children if their work ethic is very demanding and the children fail. The parents instill just enough of the social work norm in their children so that these two effects are optimally traded off. While their model is asymmetric - parents are altruistic and move first and children are selfish - our model is symmetric - the two siblings move simultaneously and may be equally altruistic towards each other. Nevertheless, the issues dealt with are related, the models similar in structure and the parametrization of preferences over consumption and effort identical.

The remainder of the essay is organized as follows. In the next section we present and solve the basic decision problem of an atomistic individual. We then prove that there exists a welfare-enhancing insurance policy. In section 4 we introduce the family by presenting the basic game between two individuals, we show that this game has a unique equilibrium, and we conduct a comparative-statics analysis of the equilibrium outcome with respect to altruism and coerced altruism. We further analyze the sustainability of coerced altruism as a social norm. In section 5 we compare formal insurance with insurance provided within the 
family. Section 6 concludes by summarizing our main results and by pointing to directions for future work. All mathematical proofs are in appendix.

\section{Selfish atomistic individuals}

We begin by presenting the backdrop, the same base-line model as in the companion paper Alger and Weibull (2007). Consider a selfish individual who feels no wish or social pressure to help others, living in an environment where insurance is not available. The individual chooses an effort level that determines the probability distribution over the possible returns, or output levels. The output is either high, $y^{H}>0$, or low, $y^{L}=y^{H} / \rho$, where $\rho>1$, the ratio between the high and low output levels, represents the riskiness of the physical environment; this is the fraction to which output is reduced in the "bad" outcome. We think of $y^{H}$ as the richness of the environment.

We assume that an individual who makes an effort yielding a success probability $p<1$ for the high output level and then consumes an amount $c>0$ of the output achieves utility

$$
u(c, p)=\ln c+\gamma \ln (1-p)
$$

where $\gamma>0$. Hence, the expected utility associated with any choice of $p \in[0,1)$ is

$$
p \ln y^{H}+(1-p) \ln y^{L}+\gamma \ln (1-p)=\ln y^{H}-(1-p) \ln \rho+\gamma \ln (1-p)
$$

As shown in Alger and Weibull (2007), this utility specification corresponds to log-linear utility in consumption and effort, with $\gamma$ as the marginal cost of effort, and with a success probability that is exponential in effort, tending to 1 as effort goes to plus infinity. ${ }^{5}$ We will refer to the quantity in (1) as material utility. (For a selfish individual as we study here, utility is material utility, while for an altruistic individual, to be studied below, utility also includes others' material utility).

The success probability $p^{0}$ that maximizes expected utility is easily found to be

$$
p^{0}=\max \left\{0,1-\frac{\gamma}{\ln \rho}\right\} .
$$

We note that the optimal effort level, when positive, is independent of the richness of the environment, $y^{H}$, higher in a riskier environment and higher when the marginal cost $\gamma$

\footnotetext{
${ }^{5}$ Let $x \geq 0$ be effort, let $u=\ln c-\beta x$ and $p=1-e^{-\theta x}$, for $\beta, \theta>0$. This is equivalent with (1) for $\gamma=\beta / \theta$.
} 
of effort is lower.

Considering the possibility that the success probability may be zero, the achieved expected material utility, or welfare, may be written:

$$
u^{0}=\max \left\{\ln y^{H}-\ln \rho, \ln y^{H}-\left(1+\frac{\gamma}{\ln \rho}\right) \ln \rho+\gamma \ln \left(\frac{\gamma}{\ln \rho}\right)-\gamma\right\} .
$$

Welfare is thus increasing in the richness of the environment, $y^{H}$, and decreasing in the riskiness of the environment, $\rho$, and in the marginal cost of effort, $\gamma$. The associated achieved expected output level, or income, is

$$
\begin{aligned}
y^{0} & =y^{L}+\left(y^{H}-y^{L}\right) p^{0} \\
& =\max \left\{\frac{1}{\rho}, 1-\left(1-\frac{1}{\rho}\right) \frac{\gamma}{\ln \rho}\right\} y^{H} .
\end{aligned}
$$

Hence, the national income of an isolated country inhabited by such selfish individuals would be increasing in the richness of their environment and decreasing in their cost of effort. For low levels of riskiness, effort is not worthwhile at all, and then national income is decreasing in the riskiness, while for high levels of riskiness, effort is worthwhile and national income is increasing in the riskiness of the environment. This non-monotonicity is illustrated in Figure 1 .

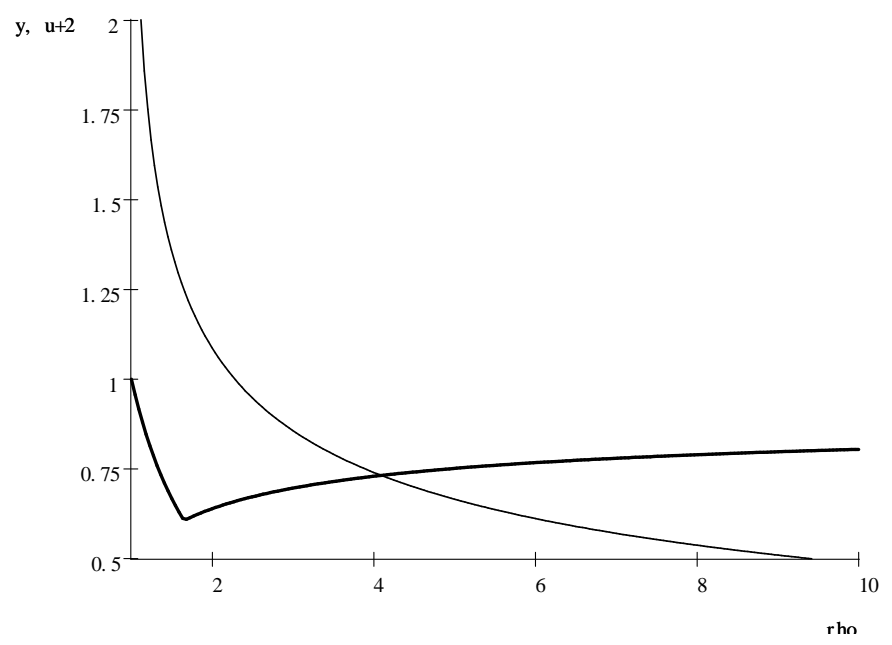

Figure 1. Income $y^{0}$ (thick curve) and utility $u^{0}+2$ (thin curve) as a functions of the riskiness $\rho$ of the environment. 


\section{Formal insurance}

Consider a large population of ex ante identical atomistic and selfish individuals facing i.i.d. risks of the type described above. By the law of large numbers, the fraction of individuals who end up with the low output is approximately $1-p^{0}$, where $p^{0}$ is the optimal success probability (2) for each individual.

If neither individual efforts nor outputs (incomes) are verifiable, then the moral hazard problem for insurance systems is overwhelming since the temptation will be strong for opportunistic individuals to insure themselves and then not exert any effort. A less overwhelming, but still significant, moral hazard problem pertains if individual efforts are not verifiable but outputs (incomes) are. We here analyze actuarially fair insurance in this case. Suppose that individual outputs (incomes) are verifiable while individual efforts are not. What would an optimal actuarially fair insurance give? If the individuals could collectively choose a compulsory insurance scheme - a form of social security — what would this then be? What effect would insurance have on the incentive to exert effort and hence on national income?

We first focus on compulsory insurance policies. These may be provided either directly by a government agency or by perfectly competitive private insurance companies. Formally,

an insurance policy is a pair $(\sigma, \pi) \in[0,1]^{2}$, where the insurance premium is $\pi y^{H}$ and the indemnity, net of the premium, to an individual who obtains the low output is $\sigma y^{H}$. Thus, an individual who receives the high output enjoys consumption $(1-\pi) y^{H}$ while an individual who receives the low output enjoys consumption $(\rho \sigma+1) y^{H} / \rho$. Given such an insurance policy $(\sigma, \pi)$, the individually optimal effort level is the same for all individuals. The decision problem faced by each individual is equivalent with that in autarky, with the original riskiness $\rho$ replaced by the (lower) riskiness

$$
\hat{\rho}=\frac{1-\pi}{\rho \sigma+1} \rho .
$$

Hence, from (2) we obtain the optimal success probability

$$
\hat{p}=\max \left\{0,1-\frac{\gamma}{\ln \hat{\rho}}\right\} .
$$

Under insurance $(\sigma, \pi)$, each individual lives in a less risky environment and thus exerts less effort than in autarky. For $\gamma<\ln \hat{\rho}$ all individuals exert positive effort under the insurance policy. For $\ln \hat{\rho}<\gamma<\ln \rho$, no individual exerts any effort under the insurance policy, although all individuals would have exerted effort in autarky.

We define an insurance policy $(\sigma, \pi) \in[0,1]^{2}$ to be optimal if it maximizes individual 
expected utility under the constraint that the policy is actuarially fair: $\hat{p} \pi=(1-\hat{p}) \sigma$. In order to characterize the optimal insurance policy, for given values of $\rho$ and $\gamma$, view the individually optimal success probability $\hat{p}$, defined in equation (5), as a function of the insurance policy $(\sigma, \pi)$ and write each individual's achieved expected utility as

$$
\hat{u}(\sigma, \pi)=\hat{p}(\sigma, \pi) \ln (1-\pi)+[1-\hat{p}(\sigma, \pi)] \ln (\sigma+1 / \rho)+\gamma \ln [1-\hat{p}(\sigma, \pi)]
$$

This defines $\hat{u}:[0,1]^{2} \rightarrow \mathbb{R}$ as a continuous function of $\sigma$ and $\pi$. By Weierstrass's Maximum Theorem there exists an optimal insurance policy. It is not difficult to show that in an environment in which effort is worthwhile in autarky, insurance is welfare enhancing:

Proposition 1 There exists at least one optimal insurance policy $(\hat{\sigma}, \hat{\pi}) \in[0,1]^{2}$. The noinsurance policy, $\sigma=\pi=0$, is suboptimal if $\gamma<\ln \rho$.

Until now we have assumed that insurance is compulsory. Suppose now it is voluntary. If it is provided by the government, and each individual can choose whether or not to buy one insurance policy $(\hat{\sigma}, \hat{\pi})$, then all individuals will do so, according to proposition 1. Suppose instead that insurance is voluntary and provided by private insurance companies. In face of the moral hazard problem - the non-verifiability of individuals' efforts - can the optimal policy be obtained by way of a perfectly competitive market? Assume, thus, that there are risk-neutral profit-maximizing insurance companies who cannot verify individual efforts, only outputs (incomes). Assume also that insurance is indivisible, that is, individuals can buy either one or zero insurance policies. If all insurance companies were to offer the optimal insurance policy $(\hat{\sigma}, \hat{\pi})$, characterized above, then it follows from proposition 1 that each individual would buy the policy (and insurance companies would just break even). There would be no way for an individual insurance company to earn positive profits by way of offering another policy $(\sigma, \pi)$. In sum: if multiple or partial purchases of insurance policies are not possible, then a perfectly competitive insurance market can deliver the optimal insurance policy to a population of atomistic and selfish individuals.

While proposition 1 establishes that each individual's achieved expected utility is higher under optimal insurance than in autarky, expected output, and hence national income, is lower:

$$
\hat{y}=y^{L}+\left(y^{H}-y^{L}\right) \hat{p}<y^{L}+\left(y^{H}-y^{L}\right) p^{0}=y^{0} .
$$

Formal insurance markets tend to be well-developed only in some countries. In many places individuals have little or no access to formal insurance, and are instead involved in risksharing arrangements at the family or the village level. We next turn to the analysis of a society where such risk-sharing is triggered by an expectation that individuals help out less 
fortunate family members.

\section{Coerced family altruism}

Following in the tradition of Smith (1790) and Edgeworth (1881) among other economists, Sen (1977) argued that individuals are not solely driven by a wish to maximize their own material welfare. In particular, Sen identified "sympathy" and "commitment" as two other motives: "when a person's sense of well-being is psychologically dependent on someone else's welfare, it is a case of sympathy," and "one way of defining commitment is in terms of a person choosing a act that he believes will yield a lower level of personal welfare to him than an alternative that is also available to him" (p.327). In this section we inject both some sympathy and some commitment into our model. Thus, assume now that individuals still work individually but belong to families, and that in case of unequal individual output levels between siblings, a rich sibling is expected to transfer resources to a poor sibling. Siblings may feel sympathy towards each other, and hence a wish to help each other, but we here focus on the case when a social norm dictates transfers that are at least as large as the transfers that would be given voluntarily in the absence of the social norm. In other words, people feel coerced to behave as if they were more altruistic towards other family members than they actually are. We take such a social norm as given in this section. In section 4.3 we analyze the robustness of such social norms.

More precisely, assume now that each individual $i$ has one sibling, denoted $i^{\prime}$, and each such pair interacts over two periods, along the lines of the model in the preceding section. Thus, in the first period, both siblings simultaneously choose their success probabilities $p_{i}$ and $p_{i^{\prime}}$. The output $y_{i}$ of individual $i$ is realized at the end of the first period. For the sake of notational and analytical convenience, we take the two siblings' outputs to be statistically independent random variables. This independence assumption can be relaxed to allow for positive correlation between outputs, but this does not give more insight into the incentive problems analyzed here (see footnote 11 in Alger and Weibull, 2007).

At the beginning of the second period, both siblings observe each others' outputs, and each sibling makes the socially sanctioned transfer to his or her sibling. After these transfers, each individual's disposable income, or consumption, therefore equals his output plus any transfer received from the sibling minus any transfer given to the sibling. Since only the net transfer matters for the final utility it suffices to define the socially sanctioned net transfer from individual $i$ to his or her sibling $i^{\prime}$ when the output vector is $\left(y_{i}, y_{i^{\prime}}\right)$, which we denote $\tau_{i}\left(y_{i}, y_{i^{\prime}}\right)$. We assume that an individual who gets a high output is expected to make a net transfer $T \in[0,1]$ to his or her sibling, should the latter's output be low. Thus, $\tau_{i}\left(y_{i}, y_{i^{\prime}}\right)=T$ 
if $\left(y_{i}, y_{i^{\prime}}\right)=\left(y^{H}, y^{L}\right), \tau_{i}\left(y_{i}, y_{i^{\prime}}\right)=-T$ if $\left(y_{i}, y_{i^{\prime}}\right)=\left(y^{L}, y^{H}\right)$, and $\tau_{i}\left(y_{i}, y_{i^{\prime}}\right)=0$ if $y_{i}=y_{i^{\prime}}$.

We analyze this interaction as a game, $\operatorname{denoted} \tilde{G}$, in which a pure strategy for individual $i$ is a success probability $p_{i} \in[0,1)$. Each strategy profile determines the total utility to sibling $i$ in each state $\left(y_{i}, y_{i^{\prime}}\right)$ :

$$
\ln \left(y_{i}-\tau_{i}\left(y_{i}, y_{i^{\prime}}\right)\right)+\alpha \ln \left(y_{i^{\prime}}+\tau_{i}\left(y_{i}, y_{i^{\prime}}\right)\right)+\gamma \ln \left(1-p_{i}\right)+\alpha \gamma \ln \left(1-p_{i^{\prime}}\right)
$$

where $\alpha \geq 0$ represents the degree of true mutual altruism between the siblings.

We assume that the socially coerced transfer from rich to poor siblings takes the form $T=\tilde{t} y^{H}$, where

$$
\tilde{t}=\frac{\rho \tilde{\alpha}-1}{\rho \tilde{\alpha}+\rho}
$$

and $\tilde{\alpha} \in[1 / \rho, 1]$. This form is analytically convenient, but also natural, since $\tilde{t} y^{H}$ is the transfer that a rich individual with true altruism $\tilde{\alpha}$ would choose to make voluntarily to a poor sibling (see equation (13) in Alger and Weibull, 2007). Hence, our assumption that the social norm dictates a transfer than is not smaller than what siblings would freely choose may be succinctly expressed as $\tilde{\alpha} \geq \alpha .^{6}$

\subsection{Equilibrium and comparative statics}

In the first period, each individual independently chooses a success probability. The (ex ante) expected total utility for individual $i$, which is also his or her payoff in game $\tilde{G}$, can be expressed as a function of the two success probabilities:

$$
\begin{aligned}
U_{i}\left(p_{i}, p_{i^{\prime}}\right) & =(1+\alpha) \ln y^{H}-\left(1-p_{i}\right)\left(1-p_{i^{\prime}}\right)(1+\alpha) \ln \rho \\
& +p_{i}\left(1-p_{i^{\prime}}\right)[\ln (1-\tilde{t})+\alpha \ln (1 / \rho+\tilde{t})] \\
& +p_{i^{\prime}}\left(1-p_{i}\right)[\ln (1 / \rho+\tilde{t})+\alpha \ln (1-\tilde{t})] \\
& +\gamma \ln \left(1-p_{i}\right)+\alpha \gamma \ln \left(1-p_{i^{\prime}}\right) .
\end{aligned}
$$

Each player has a unique best reply to the other's strategy. The following proposition characterizes the unique Nash equilibrium of $\tilde{G}$.

Proposition 2 Suppose that the two siblings are ex ante identical, with a common degree of altruism, $\alpha$, and live in a society with coerced altruism $\tilde{\alpha} \geq \max \{1 / \rho, \alpha\}$. Then $\tilde{G}$ has a

\footnotetext{
${ }^{6}$ By contrast, Alger and Weibull (2007) assume that transfers are voluntary and driven solely by true altruism. This corresponds to the special case $\tilde{\alpha}=\alpha$.
} 
unique Nash equilibrium. This equilibrium is symmetric, with common effort zero if

$$
\ln \left(\frac{\rho+1}{\rho+\tilde{\alpha} \rho}\right)+\alpha \ln \left(\frac{\tilde{\alpha}+\tilde{\alpha} \rho}{\tilde{\alpha}+1}\right)+\ln \rho \leq \gamma .
$$

Otherwise the common success probability $\tilde{p}$ is the unique zero in $(0,1)$ of

$$
(1-p-\alpha p) \ln \left(\frac{\rho+1}{\rho+\tilde{\alpha} \rho}\right)+(\alpha-p-\alpha p) \ln \left(\frac{\tilde{\alpha}+\tilde{\alpha} \rho}{\tilde{\alpha}+1}\right)+\ln \rho=\frac{\gamma}{1-p}
$$

Note that, even if $\ln \rho>\gamma$ so that the autarky effort $p^{0}$ is positive, here the success probability may be nil if $\ln \rho>\gamma$. To a relatively selfish individual, the prospect of having to support a poor sibling does not give much incentive to work hard and the prospect of being helped out if poor has a disincentive effect. In fact it is not difficult to show that $\alpha$, the common degree of true altruism, has a positive incentive effect on the success probability while the degree of coerced altruism, $\tilde{\alpha}$, has a negative effect.

Proposition 3 Suppose that the two siblings are ex ante identical, are truly altruistic towards each other of degree $\alpha \in[0,1]$, and live in a society with coerced altruism $\tilde{\alpha} \geq \alpha$, where $\rho \tilde{\alpha}>1$. Their equilibrium success probability $\tilde{p}$, is increasing in $\alpha$ and decreasing in $\tilde{\alpha}$.

Increasing true altruism entails an empathy effect: the individuals take into account the utility of the other individual to a larger extent, and therefore have an incentive to increase their effort. Increasing coerced altruism entails a free-rider effect: an increase in $\tilde{\alpha}$ means that the individual gets to keep less should he be lucky and his sibling unlucky, and gets a larger transfer in the opposite case.

\subsection{Welfare}

To make comparisons with settings where individuals are selfish we use the equilibrium expected material utility $\tilde{u}$ as a welfare measure. Proposition 2 defines the equilibrium success probability as a function of both true altruism $\alpha$ and coerced altruism $\tilde{\alpha}$, so we may write:

$$
\begin{aligned}
\tilde{u}(\alpha, \tilde{\alpha}) & =\ln y^{H}+\tilde{p}(\alpha, \tilde{\alpha})[1-\tilde{p}(\alpha, \tilde{\alpha})] \ln [(1-\tilde{t})(1 / \rho+\tilde{t})] \\
& -[1-\tilde{p}(\alpha, \tilde{\alpha})]^{2} \ln \rho+\gamma \ln [1-\tilde{p}(\alpha, \tilde{\alpha})] .
\end{aligned}
$$

We find that $\tilde{u}$ is increasing in the common degree of true altruism, for any given degree of coerced altruism, ceteris paribus. 
Proposition 4 For any $\rho>1, \gamma>0$ and $\tilde{\alpha}>1 / \rho, \tilde{u}$ is increasing in $\alpha$, for $\alpha \leq \tilde{\alpha}$.

In our companion paper we analyze the special case $\tilde{\alpha}=\alpha$, i.e., transfers are driven solely by true altruism. There we show that the level of true altruism that maximizes the expected material utility is full altruism, $\alpha=1$. Together with proposition 4 this result implies that in our model the vector of coerced and true altruism $(\tilde{\alpha}, \alpha)$ that maximizes the expected material utility involves sharing output equally, $\tilde{\alpha}=1$, and full true altruism, $\alpha=1$.

Coerced altruism arguably exists in many parts of the world. Can such a social or cultural norm be beneficial in terms of (ex ante) expected material utility? In order to analyze this question in its starkest form, consider a pair of completely selfish siblings, $\alpha=0$, who live in a society with coerced altruism of degree $\tilde{\alpha}>1 / \rho$. Equation (7) gives an expression for the ex ante expected total utility in equilibrium. In the special case of selfish siblings, this is the same as the ex ante expected material utility $\tilde{u}(0, \tilde{\alpha})$, where $\tilde{u}(0, \tilde{\alpha})$ is defined in equation (8). Figure 2 plots this expected material utility against the level $\tilde{\alpha}$ of coerced altruism, for $\rho=5$ and $\gamma=0.5$.

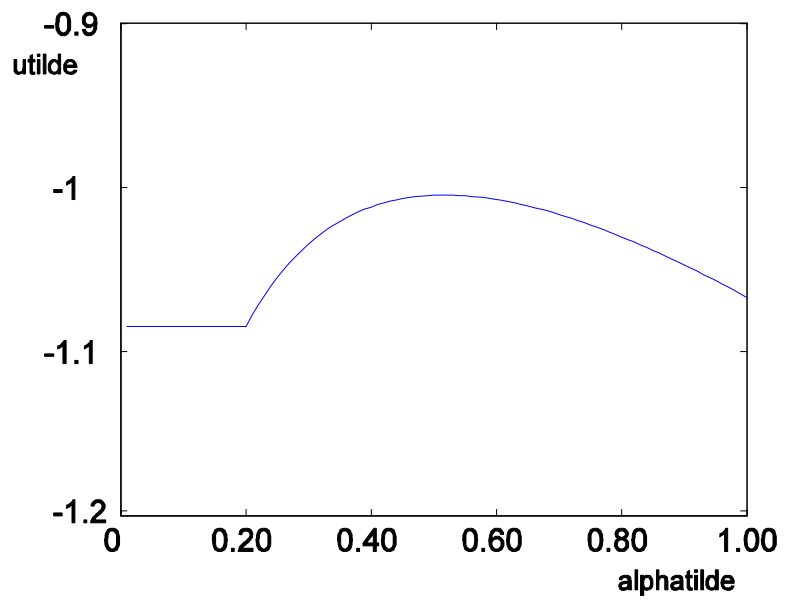

Figure 2. Expected material utility $\tilde{u}(0, \tilde{\alpha})$ of selfish individuals with coerced altruism $\tilde{\alpha}$ (for $\rho=5$, and $\gamma=0.5$ )

As $\tilde{\alpha}$ increases beyond $1 / \rho$, the smallest value of $\tilde{\alpha}$ for which a positive transfer may occur, we see that the expected material utility increases. Hence, here the marginal "benefit" of coerced altruism (the imposed mutual insurance) outweighs its marginal "cost" (reduced effort). In this example, coerced family altruism is thus advantageous ex ante, in spite of its adverse effect on effort. This can be shown more generally: Selfish siblings are better off in a society with coerced altruism than living in autarky. ${ }^{7}$ Moreover, the optimal level of coerced

\footnotetext{
${ }^{7}$ In a similar vein, Arnott and Stiglitz (1991) show that a pair of selfish siblings who cannot observe each other's efforts (and therefore not enforce transfers conditional on efforts) would nonetheless gain by agreeing
} 
altruism does not dictate that siblings should split even - the rich sibling should keep more than half of the joint output:

Proposition 5 In a society with selfish individuals $(\alpha=0)$, the level of coerced altruism that maximizes their expected material utility exceeds $1 / \rho$ and is less than 1 :

$$
\frac{1}{\rho}<\arg \max _{\tilde{\alpha} \in[0,1]} \tilde{u}(0, \tilde{\alpha}) \leq 1
$$

The intuition for the optimal $\tilde{\alpha}$ to exceed $1 / \rho>0$ is as follows. First, for $\tilde{\alpha}<1 / \rho$ no transfers are given and thus efforts are constant when $\tilde{\alpha}$ is changed. Consequently also the expected material utility is then constant. At $\tilde{\alpha}=1 / \rho$, however, material utility increases when $\tilde{\alpha}$ is marginally increased. An increase in $\tilde{\alpha}$ will obviously increase the transfer between a rich and a poor sibling. Because of the concavity of the utility from consumption, this increased insurance will enhance both siblings' ex ante expected material utility if they would not change their efforts. Consider now the effort choice by one of the siblings, $i$. By the envelope theorem, a marginal increase in $\tilde{\alpha}$ will have no first-order effect on $i^{\prime}$ s expected utility. However, also the other sibling, $i^{\prime}$, will change his or her effort. But it turns out that, precisely at $\tilde{\alpha}=1 / \rho$, also this marginal change in behavior has no first-order effect on the expected material utility of sibling $i$.

While the expected utility to selfish siblings is higher under coerced altruism than without it, efforts and thus the expected output $\tilde{y}$ is lower, where

$$
\tilde{y}=y^{L}+\left(y^{H}-y^{L}\right) \tilde{p}<y^{L}+\left(y^{H}-y^{L}\right) p^{0}
$$

\subsection{Coerced altruism as a robust social norm}

Which degree of coerced family altruism will prevail as a social norm in the long run, in a population consisting of identical selfish individuals, in a given physical environment? Suppose that a certain degree of coerced altruism, $\tilde{\alpha}$, is a social norm in a subset of the population, group $A$, while another degree of coerced altruism, $\tilde{\alpha}^{\prime}$, is the social norm in another subset of the population, group $B$. Suppose, moreover, that each group is in its corresponding equilibrium, as defined in section 4.1. Thus $\tilde{u}(0, \tilde{\alpha})$ is the expected material utility in group $A$ and $\tilde{u}\left(0, \tilde{\alpha}^{\prime}\right)$ that in group $B$-see equation (8). A situation in which $\tilde{u}\left(0, \tilde{\alpha}^{\prime}\right)<\tilde{u}(0, \tilde{\alpha})$ does not appear to be socially stable. All individuals being selfish by assumption, individuals, families and local communities in group $B$ would be keen to adopt

ex ante to a contract whereby a rich sibling would make a transfer to a poor one. 
the social norm of group $A$, since that results in higher welfare. Such a change of social norms could occur either by adaptation or by migration. Given such destabilizing possibilities, we call a degree of coerced altruism $\tilde{\alpha}$ socially robust if there exists no degree of coerced altruism $\tilde{\alpha}^{\prime} \neq \tilde{\alpha}$ such that $\tilde{u}\left(0, \tilde{\alpha}^{\prime}\right)>\tilde{u}(0, \tilde{\alpha})$. Clearly a socially robust degree of altruism, according to this definition, is an optimal degree identified in proposition 5 .

Another relevant question is the enforcement of a given degree of coerced altruism. We will not go into any depth here, only make one observation. Suppose that coerced altruism of some degree $\tilde{\alpha}$ is an internalized social norm in a population. Individuals who give a smaller transfer than $\tilde{t}$ to their sibling, when that sibling is poor and they themselves are rich, experience disutility, and more disutility the larger fraction of the population (or their peer group) adheres to the social norm. Formally, this amounts to a modification of the model above as follows. Consider a pair of identical siblings, both selfish. Let $\tilde{p}$ be the equilibrium success probability (defined in proposition 2 ) and let $z \in[0,1]$ be the population share who adhere to the norm by way of giving a transfer $t \geq \tilde{t}$ when rich and their sibling is poor (where $\tilde{t}$ is defined in equation (6)). Let $\varphi(z)$ be the disutility experienced by an individual who deviates from this norm, where $\varphi$ is an increasing function with $\varphi(0)=0$ and $\varphi(1)=\lambda>0$. Since by assumption all individuals are selfish, a deviator will not give any transfer to his or her sibling. Hence, a deviator will make an effort such that the success probability $p$ solves

$$
\begin{aligned}
& \max _{p \in[0,1]} \ln y^{H}-(1-p)(1-\tilde{p}) \ln \rho-p(1-\tilde{p}) \varphi(z) \\
& +(1-p) \tilde{p} \ln (1 / \rho+\tilde{t})+\gamma \ln (1-p) .
\end{aligned}
$$

Let $p^{d}$ be the (generically unique) solution to this program.

In this generalized model of coerced altruism among identical selfish individuals, coerced altruism of degree $\tilde{\alpha}$ will thus prevail as a social norm, $z=1$, if and only if

$$
\begin{aligned}
& \lambda p^{d}(1-\tilde{p})+\tilde{p}(1-\tilde{p}) \ln [(1-\tilde{t})(1 / \rho+\tilde{t})]-(1-\tilde{p})^{2} \ln \rho+\gamma \ln (1-\tilde{p}) \\
\geq \quad & -\left(1-p^{d}\right)(1-\tilde{p}) \ln \rho+\left(1-p^{d}\right) \tilde{p} \ln (1 / \rho+\tilde{t})+\gamma \ln \left(1-p^{d}\right) .
\end{aligned}
$$

We also note that, viewed as a game with a continuum of players, there may exist multiple equilibria for certain parameter combinations; it is possible that both $z=1$ and $z=0$ are equilibria. ${ }^{8}$ In the first equilibrium, all individuals adhere to the social norm of coerced altruism of degree $\tilde{\alpha}$ while in the second equilibrium nobody gives any transfer (and experiences

\footnotetext{
${ }^{8}$ Indeed, there may also exist a whole continuum of intermediate equilibria where the population share $z$ is such that all individuals are indifferent between adhering to the norm or deviating from it.
} 
no disutility from doing so, since everybody deviates).

Is coerced altruism easier to sustain as a social norm in a harsher climate? We can illustrate this by studying the range of $\lambda$-values for which the adherence condition (10) is met, as a function of $\rho$. Thus, in figure 3 the lower curve shows the lowest value $\lambda$, of the cost inflicted on deviators, for which coerced altruism $\tilde{\alpha}=0.25$ may be sustained as a social norm (for $\gamma=0.5$ ). As expected, the temptation to deviate from the norm is larger for larger values of $\rho$ : the threshold value increases as $\rho$ increases. The upper curve in the figure further shows that for any $\rho$ a larger punishment would be required to sustain a higher level of coerced altruism, $\tilde{\alpha}=0.5$ (see the upper curve), as expected.

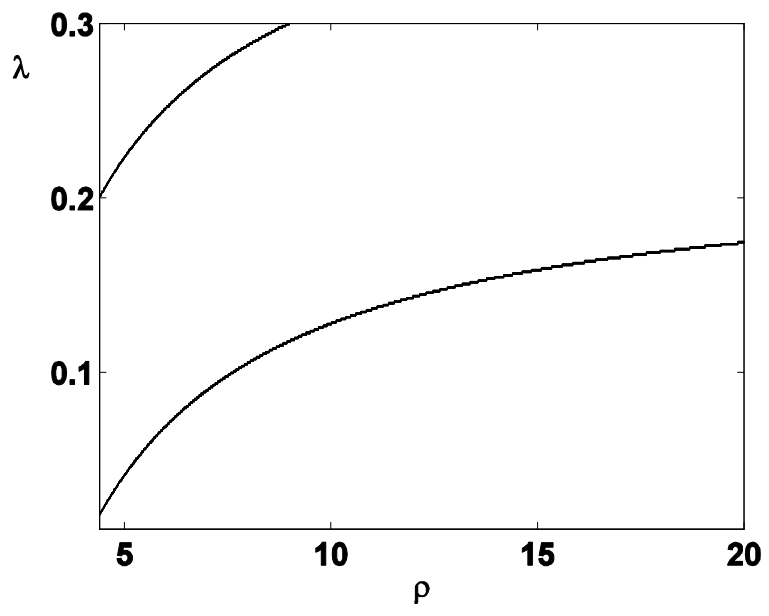

Figure 3. Sustainability of coerced altruism as a social norm, as a function of $\rho$ and $\lambda$ (lower curve: $\tilde{\alpha}=0.25$; upper curve: $\tilde{\alpha}=0.50$ )

In sum our analysis shows that informal insurance by way of coerced altruism is beneficial, and that it may arise as a social norm. However, intuition would suggest that formal insurance institutions, which pool the risks of large numbers of individuals, would be even better. It is indeed easy to establish that selfish individuals would rather live in a society where they have access to formal insurance than in one with coerced altruism, even if coerced altruism is at its optimal level:

Proposition 6 For selfish individuals, the expected material utility under coerced family altruism is lower than under optimal compulsory insurance.

However, this does not answer whether coerced altruism, if coupled with some true altruism, would also be dominated by formal insurance. We next analyze this question. In particular, we will analyze incentives for people to migrate from developing to developed countries, and compare the welfare of immigrants to that of the local population. 


\section{Formal insurance vs. coerced altruism}

For the purposes of this thought experiment we assume that coerced altruism is non-binding, i.e., $\alpha=\tilde{\alpha}$, and we will refer to $\alpha$ as the strength of family ties. By virtue of proposition 4 this assumption gives informal insurance the best possible chance against formal insurance.

Consider a pair of siblings living in some country, $A$, where no formal insurance exists, but where family ties are very strong, $\alpha_{A}=1$. Assuming that this sibling pair would keep its strong family ties if it were to move to another country, would it have an incentive to migrate to country $B$, where family ties are weak, $\alpha_{B}=0$, and where an optimal compulsory insurance system (for the inhabitants of $B$ ) is in place? If so, how would this sibling pair fare compared to the original inhabitants of country $B$, in terms of material utility and income? Let $\left(y_{A}^{H}, \rho_{A}\right)$ and $\left(y_{B}^{H}, \rho_{B}\right)$ denote the sibling pair's environment in country $A$ and $B$, respectively. An incentive for the sibling pair to migrate would obviously exist if $y_{B}^{H}>y_{A}^{H}$ and $\rho_{A}<\rho_{B}$; then the expected material utility, and hence also total (altruistic) utility, would be higher in country $B$. Consider, therefore, a situation in which the siblings' incomes, when successful, are the same in both countries, $y_{A}^{H}=y_{B}^{H}=1$, but the riskiness may differ (and country B has an insurance scheme).

In country $B$ the compulsory insurance policy $\left(\hat{\sigma}_{B}, \hat{\pi}_{B}\right)$ entails an income riskiness $\hat{\rho}_{B}$, derived from the triplet $\left(\rho_{B}, \hat{\sigma}_{B}, \hat{\pi}_{B}\right)$ according to equation (4)). If the pair of siblings moved from country $A$ to country $B$, they would represent a negligible part of the population there, and would therefore have no effect on the optimal insurance contract. They may therefore view the income riskiness $\hat{\rho}_{B}$ in country $B$ as fixed and given. Since the optimal insurance policy $\left(\hat{\sigma}_{B}, \hat{\pi}_{B}\right)$ is second best, $\hat{\rho}_{B}>1=\alpha_{A}$, a successful immigrant sibling (obtaining the high output) would make a transfer to his or her unsuccessful sibling (obtaining the low output) even in country $B$. As long as $\hat{\rho}_{B} \leq \rho_{A}$, the siblings would be as well off as in their country of origin. In fact, the next proposition implies that if this inequality is strict, they would be strictly better off in the new country, both in terms of their material utility, and in terms of their total (altruistic) utility.

Proposition 7 Consider game $G$ played by two fully altruistic siblings. In equilibrium, their expected material utility is strictly decreasing in $\rho$, ceteris paribus.

Thus, under our hypothesis $y_{A}^{H}=y_{B}^{H}$, the sibling pair would want to migrate if, and only if, the income riskiness in country $B, \hat{\rho}_{B}$, is lower than that in country $A, \rho_{A}$.

Assuming that the cost of achieving a particular success probability is the same for everyone, $\gamma_{A}=\gamma_{B}$, would the immigrated sibling pair make a higher or a lower effort than 
the locals? The only difference between the immigrants and the locals is the strength of their family ties: $\alpha_{A}=1>0=\alpha_{B}$. From the above analysis we know that individuals in altruistic families may make a higher or a lower effort than selfish individuals, depending on the environment. Thus, the immigrants may get a higher or lower expected income than the locals. In any event, the immigrants enjoy a higher expected material utility than the locals.

Until now we have assumed that insurance is compulsory in country $B$. Suppose instead that it is voluntary. If the immigrant sibling pair would not purchase any insurance policy. If $y_{A}^{H}=y_{B}^{H}$, proposition 7 implies that the sibling pair would have an incentive to migrate if, and only if, $\rho_{B} \leq \rho_{A}$. Should this condition hold and the sibling pair migrate, would they necessarily be worse off than the locals, in terms of their expected material utility, by relying solely on each others' altruism rather than on the formal insurance available in country $B$ ? Surprisingly, the answer is no.

A limitation of intrafamily transfers is the absence of transfers of resources from states of nature in which all family members are well off to states in which they all are poor. By contrast, an insurance market that pools resources of a large number of individuals exposed to idiosyncratic risks enables transfers to a poor individual even when also his or her sibling is poor. However, market insurance has a disincentive effect on effort, and typically insurance companies cannot monitor effort while in many cases family members can. The question that we address here is whether this disincentive effect can be stronger than that caused by true altruism. We illustrate the relevant trade-offs between insurance and incentives in the model outlined above by comparing the expected material utility under optimal formal insurance with that under intrafamily transfers in a few numerical examples. ${ }^{9}$

Consider first the case of $\rho_{B}=5$ and $\gamma_{A}=\gamma_{B}=0.5$. From section 2.2, we obtain (by way of Matlab), the optimal insurance coverage $\hat{\sigma} \simeq .126$. This implies an equilibrium success probability of $\hat{p} \simeq 0.489$ and an expected material utility of about $-0.98 .{ }^{10}$ The horizontal line in Figure 4 represents this material utility level, while the curve is the graph of the expected material utility to an altruistic sibling without insurance, as a function of the common degree of altruism $\alpha$. This example shows that in a society with well-functioning insurance markets, individuals with strong altruistic family ties who do not buy insurance, such as our immigrant siblings, may obtain higher expected material utility than selfish

\footnotetext{
${ }^{9}$ In fact, while we put family ties at a disadvantage by assuming the smallest possible number of family members, we put it to an advantage by assuming uncorrelated risks across family members. Families that live close together and undertake identical production tasks will face positively correlated risks and hence more rarely end up with asymmetric outcomes.

${ }^{10}$ As is well-known, in this type of model non-convexities in preferences over insurance policies may arise when the effect of the insurance on the effort is taken into account (see Arnott and Stiglitz, 1988). However, in our examples the maximization problem is well-behaved.
} 
individuals who buy formal insurance, such as the natives of country $B$.

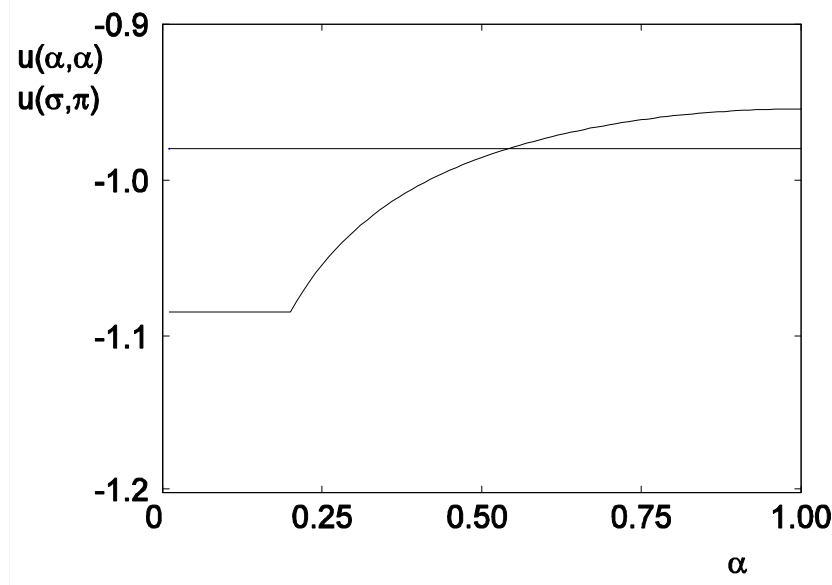

Figure 4. Expected material utility under optimal insurance $\hat{u}(\hat{\sigma}, \hat{\pi})$ (horizontal line) and under true family altruism $\tilde{u}(\alpha, \alpha)$ (the curve).

However, if the riskiness of the environment is sufficiently high, then formal insurance yields a higher expected material utility than fully altruistic family ties, for all degrees of altruism. With $\rho$ on the horizontal axis and $\gamma$ on the vertical, Figure 5 (generated with Matlab) illustrates how our fully altruistic immigrant siblings fare in comparison with the optimally insured selfish natives. In the parameter region below the curve, the former fare better, in terms of expected material utility, than the latter. ${ }^{11}$

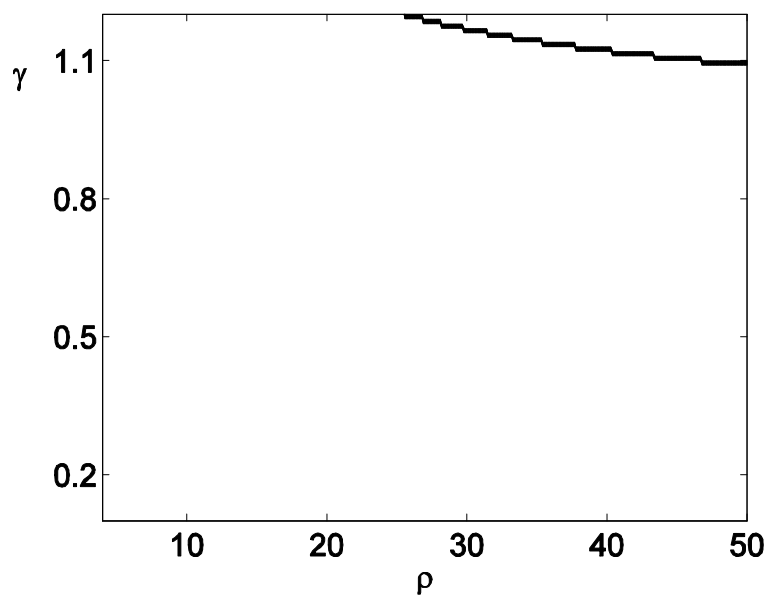

Figure 5. Optimal informal insurance, $\tilde{\alpha}=\alpha=1$, outperforms optimal formal insurance $(\hat{\sigma}, \hat{\pi})$ for values of $(\rho, \gamma)$ below the curve.

${ }^{11}$ Note that the condition $\gamma<\ln \rho$, presumed in our analysis, is met by all points in the diagram. 


\section{Conclusion}

Evidence indicates that family ties are stronger in some parts of the world than in others, and that this may have been so for several centuries. This observation prompted us to ask how the strength of family ties affects economic outcomes. Focusing on the family's potentially important role as an insurance provider for its members, we conducted a theoretical investigation of several questions, including how the strength of family ties affect economic outcomes such as the choice of a risk-reducing effort, and whether insurance provided within the family may be a good substitute for market insurance. To address these questions we proposed a simple model of individuals in an environment with uncertain outputs, where individuals may reduce the risk at some cost, and where families consist of pairs of identical individuals (which we may think of as grown-up siblings). In our model, insurance within a family took the form of transfers between the two family members, and although we allowed for siblings to be altruistic towards each other, we assumed that the transfers between them were dictated by social norms (coerced altruism). A parameter $(\rho)$ captured the riskiness of the environment (the ratio between the highest and the lowest possible output).

We found that whereas coerced altruism entails a free-rider effect and thus decreases the level of risk-reducing effort, true altruism mitigates this free-rider effect by way of an empathy effect: an altruistic individual has an incentive to increase his or her risk-reducing effort for two reasons. First, to increase the probability of being able to help a poor sibling, and, second, to decrease the probability of being unlucky and forcing the sibling to help him or her out. Furthermore we showed that even if individuals are selfish so that only the freerider effect is present, coerced altruism is beneficial from an ex ante perspective, although it gives rise to involuntary transfers ex post.

Finally, we found that if both coerced altruism and true altruism are sufficiently strong, an individual who only has access to insurance by way of coerced altruism within the family, may be better off than an individual who only has access to formal insurance. Moreover, this tends to be true if the underlying riskiness is low. If riskiness is low, selfish individuals have a low incentive to provide a risk-reducing effort even without insurance, and the moral hazard implied by formal insurance then implies that an insurance market can only play a very minor role, despite its ability to pool the resources of a very large number of individuals. By contrast, strong coerced altruism coupled with strong true altruism means that individuals have an additional incentive to provide a risk-reducing effort, namely, the utility that an altruistic individual derives from helping out the other. Where riskiness is low this empathy effect of altruism implies that individuals undertake a higher risk-reducing effort than if they were living in autarky. Thus, if individuals are rewarded for sharing with others (in 
our model this reward comes in the form of altruism, but society may also provide rewards) a high level of resource sharing within the family does not necessarily imply moral hazard: indeed, instead moral protection may arise, whereby stronger family ties may lead individuals to choose a higher effort. Compared to market insurance, the benefit of moral protection may outweigh the cost associated with the family's inability to share the resources of a very large number of individuals.

To keep our analysis simple, we modeled a family as a pair of ex ante identical individuals. It would be desirable and interesting to see whether our results extend to a richer model, with larger families, and heterogeneous individuals. It may also be fruitful to apply some of the concepts of our model to other settings, in particular to credit markets. In many developing countries, as well as in developed ones, we see microfinance systems emerge, such as the Grameen Bank in Bangladesh (for a survey, see Armendáriz and Morduch, 2005). In some of these programs poor individuals take bank loans backed by their relatives and neighbors: if a loan-taker defaults, a whole group of individuals are liable. Allowing for altruistically motivated individuals may provide additional insights regarding some of the successes of microfinance programs. 


\section{Appendix}

We here give mathematical proofs of propositions made in the text.

\section{Proof of proposition 1}

The slope of an individual's indifference curve in $(\sigma, \pi)$-space is

$$
\left.\frac{d \pi}{d \sigma}\right|_{\hat{V}}=\frac{1-\hat{p}}{\hat{p}} \cdot \frac{1-\pi}{1 / \rho+\sigma}
$$

The following equation defines the set of $(\sigma, \pi)$ satisfying budget balance:

$$
\hat{p}(\sigma, \pi) \pi-[1-\hat{p}(\sigma, \pi)] \sigma=0 .
$$

The slope of this locus is obtained as

$$
\left.\frac{d \pi}{d \sigma}\right|_{B B}=\frac{1-\hat{p}(\sigma, \pi)-(\sigma+\pi) \frac{\partial \hat{p}(\sigma, \pi)}{\partial \sigma}}{\hat{p}(\sigma, \pi)+(\sigma+\pi) \frac{\partial \hat{p}(\sigma, \pi)}{\partial \pi}} .
$$

Evaluated at $(\sigma, \pi)=(0,0)$, we thus have, for $\gamma<\ln \rho$ and hence $\hat{p}(\sigma, \pi)$ positive and differentiable at $(\sigma, \pi)=(0,0)$ :

$$
\left.\frac{d \pi}{d \sigma}\right|_{\hat{V}}=\frac{1-\hat{p}(\sigma, \pi)}{\hat{p}(\sigma, \pi)} \rho>\frac{1-\hat{p}(\sigma, \pi)}{\hat{p}(\sigma, \pi)}=\left.\frac{d \pi}{d \sigma}\right|_{B B} .
$$

It follows that there exists a budget-balanced policy with $\sigma>0$ that yields a higher expected utility than $\sigma=0$.

\section{Proof of proposition 2}

Let

$$
\begin{aligned}
\tilde{F}(p) & =(1-p-\alpha p) \ln (1-\tilde{t})+(\alpha-p-\alpha p) \ln (1+\rho \tilde{t})+\ln \rho-\frac{\gamma}{1-p} \\
& \left.\equiv \frac{\partial \widetilde{U}_{i}\left(p_{i}, p_{i^{\prime}}\right)}{\partial p_{i}}\right|_{p_{i}=p_{i^{\prime}}=p},
\end{aligned}
$$

where

$$
\tilde{t}=\frac{\tilde{\alpha} \rho-1}{\tilde{\alpha} \rho+\rho} .
$$


A common strictly positive equilibrium effort $p$ necessarily satisfies $\tilde{F}(p)=0$. For $\tilde{\alpha} \rho>1$ this yields the following polynomial equation in $p$ after some algebraic manipulation:

$$
\begin{gathered}
{\left[\ln (\tilde{\alpha} / \rho)+2 \ln \left(\frac{1+\rho}{1+\tilde{\alpha}}\right)\right] \cdot p^{2}-\left[\ln (\tilde{\alpha} / \rho)+3 \ln \left(\frac{1+\rho}{1+\tilde{\alpha}}\right)+\frac{\alpha}{1+\alpha} \ln \tilde{\alpha}\right] \cdot p} \\
+\ln \left(\frac{1+\rho}{1+\tilde{\alpha}}\right)+\frac{\alpha}{1+\alpha} \ln \tilde{\alpha}-\frac{\gamma}{1+\alpha}=0
\end{gathered}
$$

Let $A, B$, and $C$ be the coefficients in equation (13), when written in the form $A p^{2}-B p+C=$

0 . Note that $A>0$ iff $(\tilde{\alpha}-1 / \rho)(\rho-\tilde{\alpha}) \geq 0$. It follows that $B^{2}-4 A C \geq 0$ for all $\tilde{\alpha} \in[0,1]$, $\rho>1$ and $\gamma \geq 0$ such that $\tilde{\alpha} \rho \geq 1$, for $B^{2}-4 A C>(2 A-B)^{2}$ iff $A(B-A-C)>0$ iff $B-A-C>0$ iff $\gamma /(1+\alpha) \geq 0$. The two roots are

$$
q_{1}=\frac{B-\sqrt{B^{2}-4 A C}}{2 A} \quad \text { and } \quad q_{2}=\frac{B+\sqrt{B^{2}-4 A C}}{2 A}
$$

and $A>0$ implies $q_{2} \geq q_{1}$.

Next we prove that $q_{2}>1$ when $\tilde{\alpha} \rho>1$ and $\gamma>0$. For this purpose, note that $q_{2}>1$ iff $\sqrt{B^{2}-4 A C}>2 A-B$ iff $B^{2}-4 A C>(2 A-B)^{2}$ iff $A(A-B+C)<0$, an inequality that holds if $\tilde{\alpha} \in[0,1], \rho>1, \tilde{\alpha} \rho>1$ and $\gamma>0$.

It remains to show that the smaller root $q_{1}$ is less than 1 . This follows from the fact that $\tilde{F}$ is continuous, $\lim _{p \rightarrow 1} \tilde{F}(p)=-\infty$, and $\lim _{p \rightarrow-\infty} \tilde{F}(p)=+\infty$. To see the last property note that the coefficient for $p$ is negative when $\tilde{\alpha} \rho>1$, since

$$
\ln \frac{1+\rho}{1+\tilde{\alpha}}+\ln \frac{\tilde{\alpha}(1+1 / \rho)}{1+\tilde{\alpha}}>0 \Leftrightarrow(\tilde{\alpha}-1 / \rho)(\rho-\tilde{\alpha})>0 .
$$

Finally, we note that $p>0 \Longleftrightarrow \tilde{F}(0)>0 \Leftrightarrow$

$$
\begin{aligned}
\gamma & <\alpha \ln \tilde{\alpha}+(1+\alpha) \ln \left(\frac{1+\rho}{1+\tilde{\alpha}}\right) \\
& \Leftrightarrow \gamma-\ln \rho<\ln \left(\frac{1+\rho}{1+\tilde{\alpha}}\right)+\alpha \ln \left(\frac{\tilde{\alpha}(1+\rho)}{1+\tilde{\alpha}}\right)-\ln \rho
\end{aligned}
$$

For $\alpha=0$ and $\tilde{\alpha}>\beta$ this condition is more stringent than the assumption that $\gamma<\ln \rho$, since

$$
\ln \left(\frac{1+1 / \rho}{1+\tilde{\alpha}}\right)<0 .
$$




\section{Proof of proposition 3}

A necessary first-order condition for an interior and symmetric Nash equilibrium $\tilde{p}$ is $\tilde{F}(\tilde{p})=$ 0 , which may be written

$$
\tilde{F}(\tilde{p})=\alpha \ln \tilde{\alpha}+(1+\alpha) \ln \left(\frac{1+\rho}{1+\tilde{\alpha}}\right)-(1+\alpha)\left(\ln \left(\frac{1+\rho}{1+\tilde{\alpha}}\right)+\ln \left(\frac{\tilde{\alpha}(1+1 / \rho)}{1+\tilde{\alpha}}\right)\right) p-\frac{\gamma}{1-p}=0 .
$$

This equation implicitly defines $\tilde{p}$ as a function of $\alpha$ and $\tilde{\alpha}$. Differentiation of the equation $\tilde{F}(\tilde{p})=0$ with respect to $\tilde{\alpha}$ gives

$$
\frac{\partial \tilde{p}(\tilde{\alpha}, \alpha)}{\partial \tilde{\alpha}}=\frac{[1-\tilde{p}(\tilde{\alpha}, \alpha)](\alpha-\tilde{\alpha})+\tilde{p}(\tilde{\alpha}, \alpha)(\alpha \tilde{\alpha}-1)}{\tilde{\alpha}(1+\tilde{\alpha})\left[\frac{\gamma}{[1-\tilde{p}(\tilde{\alpha}, \alpha)]^{2}}+(1+\alpha) \ln \left(\rho \tilde{\alpha}\left(\frac{1+1 / \rho}{1+\tilde{\alpha}}\right)^{2}\right)\right]}
$$

where $\ln \left(\rho \tilde{\alpha}\left(\frac{1+1 / \rho}{1+\tilde{\alpha}}\right)^{2}\right) \geq 0$ iff $(\tilde{\alpha}-1 / \rho)(1-\tilde{\alpha} / \rho) \geq 0$. Hence, $\partial \tilde{p}(\tilde{\alpha}, \alpha) / \partial \tilde{\alpha}<0$ when $\alpha<\tilde{\alpha}$.

Differentiation of the equation $\tilde{F}(\tilde{p})=0$ with respect to $\alpha$ gives

$$
\frac{\partial \tilde{p}(\tilde{\alpha}, \alpha)}{\partial \alpha}=\frac{[1-\tilde{p}(\tilde{\alpha}, \alpha)] \ln \left(\frac{\tilde{\alpha}(1+\rho)}{1+\tilde{\alpha}}\right)+\tilde{p}(\tilde{\alpha}, \alpha) \ln \left(\frac{1+\tilde{\alpha}}{1+1 / \rho}\right)}{\frac{\gamma}{[1-\tilde{p}(\tilde{\alpha}, \alpha)]^{2}}+(1+\alpha) \ln \left(\rho \tilde{\alpha}\left(\frac{1+1 / \rho}{1+\tilde{\alpha}}\right)^{2}\right)}>0
$$

\section{Proof of proposition 4}

Assume a degree of coerced altruism $\tilde{\alpha}$, and hence a transfer $\tilde{t}$ (see equation (6)). For any common success probability $p$ the expected material utility to a sibling is

$$
\begin{aligned}
v(p)= & \gamma \ln (1-p)-(1-p)^{2} \ln \rho \\
& +p(1-p)[\ln (1-\tilde{t})+\ln (1 / \rho+\tilde{t})]
\end{aligned}
$$

Let $\tilde{p}(\alpha, \tilde{\alpha})$ be the unique success probability in game $\tilde{G}$. Then the expected material utility may be written as follows:

$$
\begin{aligned}
\tilde{u}(\alpha, \tilde{\alpha})= & v(\tilde{p}(\alpha, \tilde{\alpha})) \\
= & \gamma \ln [1-\tilde{p}(\alpha, \tilde{\alpha})]-[1-\tilde{p}(\alpha, \tilde{\alpha})]^{2} \ln \rho \\
& +\tilde{p}(\alpha, \tilde{\alpha})[1-\tilde{p}(\alpha, \tilde{\alpha})][\ln (1-\tilde{t})+\ln (1 / \rho+\tilde{t})]
\end{aligned}
$$




$$
\frac{\partial \tilde{u}(\alpha, \tilde{\alpha})}{\partial \alpha}=\frac{\partial v(p)}{\partial p} \underset{\mid p=\tilde{p}(\alpha, \tilde{\alpha})}{ } \cdot \frac{\partial \tilde{p}(\alpha, \tilde{\alpha})}{\partial \alpha} .
$$

From the proof of Proposition 3 we know that the second factor is positive, implying that $\frac{\partial \tilde{u}(\alpha, \tilde{\alpha})}{\partial \alpha}$ has the same sign as $\left.\frac{\partial v(p)}{\partial p}\right|_{\mid p=\tilde{p}(\alpha, \tilde{\alpha})}$. It thus remains to show that, for a given $\tilde{\alpha}$, $\frac{\partial v(p)}{\partial p}_{\mid p=\tilde{p}(\alpha, \tilde{\alpha})}>0$ for all $\alpha<\tilde{\alpha}$. This is achieved by proving that, at a fixed and given equilibrium transfer $\tilde{t}>0, v$ is strictly concave in $p$, and reaches its maximum at some $p^{v}>\tilde{p}(\alpha, \tilde{\alpha})$. First, we can easily see that $v$ is strictly concave, since

$$
v^{\prime \prime}(p)=-2 \ln \rho-2[\ln (1-\tilde{t})+\ln (1 / \rho+\tilde{t})]-\frac{\gamma}{(1-p)^{2}}<0 .
$$

Second $p^{v}$ is defined by the first-order condition

$$
(1-2 p) \ln (1-\tilde{t})+(1-2 p) \ln (1+\rho \tilde{t})+\ln \rho=\frac{\gamma}{1-p} .
$$

Compare this with the equation defining the equilibrium probability $\tilde{p}$, which is the value of $p$ satisfying:

$$
(1-p-\alpha p) \ln (1-\tilde{t})+(\alpha-p-\alpha p) \ln (1+\rho \tilde{t})+\ln \rho=\frac{\gamma}{1-p} .
$$

The right-hand side in these equations being increasing in $p$, a sufficient condition for $\tilde{p}<p^{v}$ is that the left-hand side in (14) be larger than the left-hand side in (15) for any $p \in[0,1$ ), or, equivalently, that

$$
(1-\alpha)[(1-p) \ln (1+\rho \tilde{t})-p \ln (1-\tilde{t})]>0,
$$

which is true for any $p \in[0,1)$, and $\tilde{t}>0$.

\section{Proof of proposition 5}

For $\alpha=0$ we get from (7):

$$
\begin{aligned}
\tilde{U}_{i}\left(p_{i}, p_{i^{\prime}}\right) & =-\left(1-p_{i}\right)\left(1-p_{i^{\prime}}\right) \ln \rho+p_{i}\left(1-p_{i^{\prime}}\right) \ln (1-\tilde{t}) \\
& +p_{i^{\prime}}\left(1-p_{i}\right) \ln (1 / \rho+\tilde{t})+\gamma \ln \left(1-p_{i}\right),
\end{aligned}
$$

where $\tilde{t}$ is given in (6). Hence, at $p_{i}=p_{i^{\prime}}=\tilde{p}(0, \tilde{\alpha})$ : 


$$
\begin{aligned}
\frac{\partial}{\partial \tilde{\alpha}} \tilde{U}_{i}\left(p_{i}, p_{i^{\prime}}\right) & =\frac{\partial \tilde{U}_{i}\left(p_{i}, p_{i^{\prime}}\right)}{\partial p_{i}} \frac{\partial \tilde{p}(0, \tilde{\alpha})}{\partial \tilde{\alpha}}+\frac{\partial \tilde{U}_{i}\left(p_{i}, p_{i^{\prime}}\right)}{\partial p_{i^{\prime}}} \frac{\partial \tilde{p}(0, \tilde{\alpha})}{\partial \tilde{\alpha}} \\
& -\tilde{p}(0, \tilde{\alpha})[1-\tilde{p}(0, \tilde{\alpha})] \frac{1}{1-\tilde{t}} \frac{d \tilde{t}}{d \tilde{\alpha}} \\
& +\tilde{p}(0, \tilde{\alpha})[1-\tilde{p}(0, \tilde{\alpha})] \frac{1}{1 / \rho+\tilde{t}} \frac{d \tilde{t}}{d \tilde{\alpha}}
\end{aligned}
$$

Using the two first-order conditions $\frac{\partial \tilde{U}_{i}\left(p_{i}, p_{i^{\prime}}\right)}{\partial p_{i}}=0$ and $\frac{\partial \tilde{U}_{i^{\prime}}\left(p_{i}, p_{i^{\prime}}\right)}{\partial p_{i^{\prime}}}=0$, evaluated at $p_{i}=p_{i^{\prime}}=$ $\tilde{p}(0, \tilde{\alpha})$, this simplifies to

$$
\begin{aligned}
\frac{\partial}{\partial \tilde{\alpha}} \tilde{U}_{i}\left(p_{i}, p_{i^{\prime}}\right)= & \tilde{p}(0, \tilde{\alpha})[1-\tilde{p}(0, \tilde{\alpha})]\left[\frac{1}{1 / \rho+\tilde{t}}-\frac{1}{1-\tilde{t}}\right] \frac{d \tilde{t}}{d \tilde{\alpha}} \\
& +\left[\ln \left(\frac{1 / \rho+\tilde{t}}{1-\tilde{t}}\right)+\frac{\gamma}{1-\tilde{p}(0, \tilde{\alpha})}\right] \frac{d \tilde{t}}{d \tilde{\alpha}} .
\end{aligned}
$$

For all $\tilde{\alpha}<1 / \rho$ we have $\tilde{t}=0$, and hence $\frac{\partial}{\partial \tilde{\alpha}} \tilde{U}_{i}\left(p_{i}, p_{i^{\prime}}\right)=0$. For all $\tilde{\alpha}>1 / \rho$, the first square bracket is positive, and equals $\rho-1>0$ for $\tilde{\alpha} \rho=1$. Since $\frac{d \tilde{t}}{d \tilde{\alpha}}>0$ for all $\tilde{\alpha} \geq 1 / \rho$, we conclude that the first term is positive. As for the second term we note that the square bracket vanishes when $\tilde{\alpha} \rho=1$ because then $\tilde{t}=0$, and $\tilde{p}(0, \tilde{\alpha})$ is defined by $\tilde{F}(p)=0$.

At $\tilde{\alpha}=1$, the first square bracket is zero, and so is the first term in the second square bracket, so that only $\frac{\gamma}{1-\tilde{p}(0, \tilde{\alpha})} \frac{\partial \tilde{p}(0, \tilde{\alpha})}{\partial \tilde{\alpha}}$ remains, which by proposition 3 is non-positive.

\section{Proof of proposition 6}

For a given effort level $p$, the expected material utility for a selfish individual under coerced altruism with a transfer $\tilde{t}$ equals

$$
(1-p)^{2} \ln y^{L}+p(1-p) \ln \left(y^{L}+\tilde{t}\right)+p^{2} \ln y^{H}+p(1-p) \ln \left(y^{H}-\tilde{t}\right) .
$$

For a given effort level $p$, the expected material utility for a selfish individual under compulsory insurance $(\sigma, \pi)$ with $\sigma=p \tilde{t}$ and $\pi=(1-p) \tilde{t}$ (note that such an insurance would be budget-balanced) equals

$$
(1-p) \ln \left(y^{L}+p \tilde{t}\right)+p \ln \left[y^{H}-(1-p) \tilde{t}\right]
$$

which may be rewritten as 


$$
(1-p) \ln \left[(1-p) y^{L}+p\left(y^{L}+\tilde{t}\right)\right]+p \ln \left[p y^{H}+(1-p)\left(y^{H}-\tilde{t}\right)\right]
$$

Due to the strict concavity of the logarithm function this is strictly greater than the expression in (16). Moreover, with formal insurance the individual chooses the effort level that maximizes his expected material utility, which therefore must be higher than with coerced altruism.

\section{Proof of proposition 7}

From proposition 4 in Alger and Weibull (2007) we know that if $\alpha=1$ the equilibrium expected material utility equals the maximum value of

$$
W(p, t)=p(1-p)[\ln (1-t)+\ln (1 / \rho+t)]-(1-p)^{2} \ln \rho+\gamma \ln (1-p)
$$

where

$$
t=\max \left\{0, \frac{\alpha \rho-1}{1+\alpha}\right\},
$$

and $(p, t) \in[0,1]^{2}$. In particular, $t=(1-1 / \rho) / 2$ and there exists a unique $p$ satisfying the following necessary first-order condition:

$$
\frac{\partial W(p, t)}{\partial p}=(1-2 p) \ln (1-t)+(1-2 p) \ln (1+\rho t)+\ln \rho-\frac{\gamma}{1-p}=0
$$

which defines $p$ as a function of $\rho$. We may therefore write the expected material utility as follows:

$$
Z(p(\rho), \rho)=p(\rho)[1-p(\rho)] 2 \ln \frac{1+1 / \rho}{2}-[1-p(\rho)]^{2} \ln \rho+\gamma \ln [1-p(\rho)]
$$

Differentiation yields:

$$
\begin{aligned}
\frac{d}{d \rho} Z(p(\rho), \rho) & =\frac{\partial Z(p(\rho), \rho)}{\partial p} \frac{d p(\rho)}{d \rho}+\frac{\partial Z(p(\rho), \rho)}{\partial \rho} \\
& =\frac{\partial Z(p(\rho), \rho)}{\partial \rho},
\end{aligned}
$$

where the last equality follows from the definition of $p(\rho)$. Finally, we obtain:

$$
\frac{\partial Z(p(\rho), \rho)}{\partial \rho}=\rho[1-p(\rho)]+p(\rho)[1-p(\rho)] \frac{2}{1+1 / \rho}>0 .
$$


We have now shown that if $\alpha=1$ the individual expected material utility decreases as $\rho$ increases. Since each individual's utility is the sum of both siblings' expected material utilities this implies that the expected utility also decreases as $\rho$ increases.

\section{References}

Alesina, A. \& Giuliano, P., 2007. The power of the family. NBER Working Paper 13051.

Alger, I. \& Weibull, J.W., 2007. The fetters of the sib: Weber meets Darwin. Stockholm School of Economics Working Paper.

Armendáriz, B. \& Morduch, J., 2005. The economics of microfinance. Cambridge, MA: MIT Press.

Arnott, R. \& Stiglitz, J.E., 1988. The basic analytics of moral hazard. Scandinavian Journal of Economics, 90, p.383-413.

Arnott, R. \& Stiglitz, J.E., 1990. The welfare economics of moral hazard. NBER Working Paper 3316.

Arnott, R. \& Stiglitz, J.E., 1991. Moral hazard and nonmarket institutions: dysfunctional crowding out of peer monitoring? American Economic Review, 81, p.179-190.

Azam, J.P. \& Gubert, F., 2005. Those in Kayes. The impact of remittances on their recipients in Africa. Revue Economique, 56, p.1331-1358.

Banfield, E., 1958. The moral basis of a backward society. Chicago, IL: Free Press.

Becker, G.S., 1974. A theory of social interactions. Journal of Political Economy, 82, p.1063-1093.

Bennardo, A. \& Chiappori, P.-A. , 2003. Bertrand and Walras equilibria under moral hazard. Journal of Political Economy, 111, p.785-817.

Bramoullé, Y. \& Kranton, R., 2006. Risk-sharing networks. forthcoming, Journal of Economic Behavior and Organization.

Broberg T., Ellingsen, T. \& Johannesson, M., 2007. Is generosity involuntary? Economic Letters, 94, p.32-37.

Bruce, N. \& Waldman, M., 1990. The rotten-kid theorem meets the Samaritan's dilemma. Quarterly Journal of Economics, 105, p.155-165. 
Buchanan, J.M., 1975. The Samaritan's dilemma. In Phelps, E., ed. Altruism, morality, and economic theory. New York: Russell Sage Foundation.

Chami, R., 1998. Private income transfers and market incentives. Economica, 65, p.557580 .

Chen, Z. \& Woolley, F., 2001. A Cournot-Nash model of family decision making. Economic Journal, 111, p.722-748.

Coate, S., 1995. Altruism, the Samaritan's dilemma, and government transfer policy. American Economic Review, 85, p.46-57.

Coate, S. \& Ravallion, M., 1993. Reciprocity without commitment: characterization and performance of informal insurance arrangements. Journal of Development Economics, 40, p.1-24.

Cox, D., Galasso, E. \& Jimenez, E., 2006. Private transfers in a cross section of developing countries," CRR Working Paper 2006-2.

Cox, D. \& Jimenez, E., 1990. Achieving social objectives through private transfers: a review. World Bank Research Observer, 5, p.205-18.

Dana J., Cain, D.M. \& Dawes, R.M., 2006. What you don't know won't hurt me: costly (but quiet) exit in dictator games. Organizational Behavior and Human Decision Processes, 100, p.193-201.

Dostie, B. \& Vencatachellum, D., 2006. Compulsory and voluntary remittances: evidence from child domestic workers in Tunisia. In Mourji, F., Decaluwé, B. \& Plane, P., eds. Le développement face à la pauvreté. Paris: Economica.

Edgeworth, F.Y., 1881. Mathematical psychics: an essay on the application of mathematics to the moral sciences. London: Kegan Paul.

Etounga-Manguelle, D., 2000. Does Africa need a cultural adjustment program? In Harrison, L.E. \& Huntington, S.P., eds. Culture matters: how values shape human progress. New York, NY: Basic Books.

Foster, A. \& Rosenzweig, M.R., 2001. Imperfect commitment, altruism and the family: evidence from transfer behaviour in low-income rural areas. Review of Economics and Statistics, 83, p.389-407.

Genicot, G. \& Ray, D., 2003. Group formation in risk-sharing arrangements. Review of Economic Studies, 70, p.87-113.

Helpman, E. \& Laffont, J.-J., 1975. On moral hazard in general equilibrium theory. Journal of Economic Theory, 10, p.8-23. 
Kimball, M.S., 1988. Farmers' cooperatives as behavior toward risk. American Economic Review, 78, p.224-232.

Kohler, H.-P. \& Hammel, E.A., 2001. On the role of families and kinship networks in pre-industrial agricultural societies: an analysis of the 1698 Slovenian census. Journal of Population Economics, 14, p.21-49.

Laferrère, A. \& Wolff, F.-C., 2006. Microeconomic models of family transfers. In Kolm, S.-C. \& Ythier, J.M., eds. Handbook of Reciprocity, Giving and Altruism. Amsterdam: North-Holland.

Ligon, E., Thomas, J.P., \& Worrall, T., 2002. Informal insurance arrangements with limited commitment: theory and evidence from village economies. Review of Economic Studies, 69 , p.209-244.

Lindbeck, A. \& Weibull, J.W., 1988. Altruism and time consistency: the economics of fait accompli. Journal of Political Economy, 96, p.1165-1182.

Lindbeck, A. \& Nyberg, S., 2006. Raising children to work hard: altruism, work norms and social insurance. Quarterly Journal of Economics, 121, p.1473-1503.

Mendelek Theimann, N., 2006. The lions mark their territory: the African thought system. In April, K. \& Shockley, M., eds. Diversity in Africa. Basingstoke: Palgrave Macmillan.

Miller, D. \& Paulson, A.L., 1999. Informal insurance and moral hazard: gambling and remittances in Thailand. Mimeo Princeton and Northwestern Universities.

Posner, R., 1980. A theory of primitive society, with special reference to law. Journal of Law and Economics, 23, p.1-53.

Sen, A.K., 1977. Rational fools: a critique of the behavioral foundations of economic theory. Philosophy and Public Affairs, 6, p.317-344.

Sen, A.K., 1983. Economics and the family. Asian Development Review, 1, p.14-26.

Sen, A.K., 1987. On ethics and economics. Oxford: Blackwell.

Smith, A., 1790. The theory of moral sentiments. London: A. Millar.

Townsend, R.M., 1994. Risk and insurance in village India. Econometrica, 62, p.539-591.

Weber, M., 1951. The religion of China. New York, NY: Macmillan. 